\title{
Um Trips como Praga do Piquiá
}

\author{
Joachim Adis ( ${ }^{\circ}$ ) \\ Warwick Estevam Kerr (**)
}

Em março de 1977 observou-se no terreno do INPA o ataque de um piquiá (Caryocar villosum (Aubl.) Pers.) pelo trips (Thysanoptera). Contaram-se mais de 10.000 larvas e animais adultos nas folhas da planta com uma idade de cerca de 3 anos. Segundo o Dr. R. zur Strassen (Senckenberg-Institut Frankfurt, Alemanha Oc.J, trata-se de Holopothrips anacardii Hood. Os animais adultos têm um comprimento de cerca de $1,7 \mathrm{~mm}$ (com apêndice, cerca de $2,0 \mathrm{~mm}$ ). Sua característica é a dupla cor: corpo e pernas são amarelo-limão, sendo os últimos 2 segmentos abdominais inteiramente marron ou preto-marron (mais informações para determinação, cf. Hood, 1941). Imagens desta espécie apareceram em 1925 também em março - em pequeno número, nas folhas de Anacardium occidentale L. nas proximidades da Bahia. Caryocar villosum é uma planta de importância econômica, cultivada na Amazônia pela utilidade de seus frutos e sua madeira (Prance, 1975). O ataque ex- tremamente forte de trips fez murchar os novos rebentos de folhas. No caso de um aparecimento em massa durante o tempo de chuva - sobretudo nas plantações - há que considerar o Holopothrips anacardii como praga especialmente dos piquiás jovens. A planta liberta-se quase completamente deles quando faz uma troca de folhas.

\section{MATERIAL}

10 fêmeas, 5 machos e 6 larvas no Museu Entomológico do INPA, Manaus/Brasil.

\section{BIBLIOGRAFIA}

Hood, D. J.

1941 - A century of New American Thysanoptera III. Rev. de Entomologia 12 (3): 547-6̂78.

Prance, G. T. \& Silya, M. Freitas da

1975 - Árvores de Manaus. Manaus, INPA, 312 p.

(Aceito para publicação em 11/07/79)

(") - II. Zoologisches Institut, Berlinerstr. 28, D-34 Göttingen, Alemanha Oc.

("*) - Instituto Nacional de Pesquisas da Amazônia, Manaus. 